\title{
Sandro Borelli e a dramaturgia da violência
}

DORIA, Gisela ${ }^{1}$

Resumo:

Esse artigo problematiza aspectos ligados à dramaturgia na dança contemporânea, tendo como eixo três obras do coreógrafo paulista Sandro Borelli. Em seu extenso diálogo com a obra de Kafka, Borelli levou para a cena seis coreografias inspiradas em textos originais. Foi feito um recorte a partir da Trilogia Kafka, composta pelas coreografias inspiradas nas obras homônimas: Metamorfose, Carta ao Pai e O processo.

Palavras-chave:

Dança Contemporânea, Dramaturgia, Cartografia.

Abstract:

This article will problematize aspects releated to dramaturgy in the contemporary dance, having as its axis three works by the coreographer from Sao Paulo Sandro Borelli. In its consistent dialogue with the work of Kafka, Borelli staged six coreographies inspired by its original texts. Here, I will focus on the Kaffa's Trilogy, composed by coreographies inspired by the homonimous pieces: Metamorphosis, Letter to my father and The Process.

Keywords:

Contemporary Dance, Dramaturgy, Cartography.

Doutoranda em Artes da Cena pela Universidade Estadual de Campinas. Bolsista da Coordenação de Aperfeiçoamento de Pessoal de Nível Superior (CAPES). E-mail: gisadoria@gmail.com. 
"Nunca presto atenção aos preâmbulos", afirma a menina Bürstner à personagem $\mathrm{K}$ em O processo (Kafka, 1997, p. 20). Assim se configura a dramaturgia de Sandro Borelli, crua, direta ao ponto, sem preâmbulos. Pouca luz, pouco cenário, pouco figurino. Pouca dança?

Autor de um repertório coreográfico consistente, Borelli está à frente de sua companhia há mais de 15 anos. Dono de uma linguagem autoral, que valoriza a economia de recursos cênicos e o diálogo constante com outros autores, seja da literatura, da poesia ou das artes visuais, Borelli constrói suas obras a partir do movimento. Se, em suas obras, a "inspiração" vem da interlocução com outras interfaces, é o seu corpo e o corpo de seus bailarinos que falam em primeiro lugar.

Embora Borelli seja um artista da dança especificamente, ao analisar as criações do coreógrafo paulistano, ex-bailarino do Balé da Cidade de São Paulo, é possível perceber que seu modelo de trabalho assemelha-se, de certo modo, com o proposto por Bertolt Brecht. Guardadas as diferenças entre os trabalhos dos dois artistas, se entendermos a evolução do conceito de dramaturgia na prática teatral podemos perceber de forma mais precisa como se dá a dramaturgia da dança na obra aqui referida: a da Borelli Cia. de Dança.

\section{Dramaturgia, sim}

Ainda que o termo dramaturgia e seus desdobramentos (dramaturg, dramaturgista, dramaturgo) gerem polêmica e discussão no âmbito da dança, assim como no do teatro, é possível perceber nitidamente, sobretudo na dança contemporânea a partir dos anos 1980, a presença crescente do dramaturgista em diversas obras coreográficas, como aponta Saadi, a partir de uma citação de Barnard Dort: "o termo dramaturgia testemunha a evolução da prática teatral" (DORT, apud SAADI, 2011, p. 108). Se, a princípio, o conceito de dramaturgia estava relacionado, exclusivamente, com a criação do texto dramático, no decorrer do século XX essa noção foi significativamente ampliada, ao abranger diversos aspectos da obra cênica. E não somente o teatro "explodiu" a noção de dramaturgia como a dança apropriou-se dessa noção, trazendo para si a referência e a necessidade de um pensamento consciente da dramaturgia como elemento fundamental na construção de um espetáculo.

De fato, falar de dramaturgia na dança implica, necessariamente, refletir sobre a dramaturgia no teatro. A pesquisa sobre dramaturgia, no âmbito teatral, é significativamente mais extensa do que aquela em dança; nesta última, a dramaturgia passou por um nítido processo transforma- 
tivo no decorrer do século passado, principalmente em sua segunda metade.

Se por um lado, o termo "dramaturgia",, no ocidente, remeteu, desde a Grécia Clássica até meados do século XX, à arte de escrever textos dramáticos - portanto, desde Aristóteles, passando por Boileau e Lessing, dentre muitos outros - por outro lado, uma nova concepção de dramaturgia emergiu no ocidente durante a segunda metade do mesmo século. Não é exagero afirmar que a partir das teorias e práticas teatrais de Bertold Brecht existe uma antes e depois na dramaturgia ocidental. Essa nova perspectiva representa, por sua vez, uma ampliação em relação à concepção original da dramaturgia para além do texto dramático na construção de uma peça teatral.

De fato, entre os artistas que contribuíram para o surgimento e o desenvolvimento desse conceito, cabe ressaltar o trabalho desenvolvido por Bertolt Brecht, assim como as elaborações feitas por Antonin Artaud. De maneiras diferentes, eles foram importantes para a consolidação e a ampliação da noção de dramaturgia para além da confecçāo de textos dramáticos. A partir do trabalho desenvolvido por Brecht, a noção de dramaturgia passa a estar relacionada tanto com a produção de textos dramáticos, quanto com a articulação dos diversos elementos que compõem a cena. Com o dramaturgo alemão, surge de maneira consistente a figura do dramaturg, ou seja, de um profissional que atua como um criador polivalente da cena, que articula o texto escrito aos outros elementos cênicos.

Já no caso de Artaud, o texto deixa de ser a matriz única de significação do teatro e propõe-se à dissolução de uma relação hierárquica entre os elementos da cena. Assim, apesar de manifestarem percepções diferentes sobre o teatro, tanto Brecht quanto Artaud abriram caminhos para o reconhecimento de uma noção de dramaturgia que não está relacionada, especificamente, com o texto escrito, mas sim com o funcionamento e com a articulação do fenômeno espetacular que se materializa cenicamente.

No que diz respeito aos desdobramentos pós-brechtianos relacionados com essa ampliação da noção de dramaturgia, o trabalho desenvolvido por Eugenio Barba deve ser considerado. Em suas elaborações teórico-práticas, ele propõe três noções de dramaturgia: 1) a dramaturgia orgânica ou dinâmica, que envolve a composição dos ritmos e dos dinamismos, que agem, por sua vez, sobre o espectador em nível nervoso, ou seja, sensorial; 2) a dramaturgia narrativa, que entrelaça os acontecimentos, as personagens e orienta os espectadores em relação ao sentido do que estão vendo; e 3) a dramaturgia das 
mudanças de estado, que emerge quando o conjunto do que é mostrado consegue evocar algo diferente, inesperado, como o desenvolvimento do canto e da música por meio dos harmônicos, permitindo uma outra linha sonora (Barba, 1999, p. 16).

Em relação à dramaturgia da dança, são poucos os autores que, de fato, desenvolveram uma pesquisa mais aprofundada. No entanto, ainda que sejam raras as fontes bibliográficas, é possível detectar um crescente interesse dos pesquisadores sobre tal temática. Uma série de artigos foi publicada, recentemente, em livros e revistas nacionais; podemos citar a revista Sala Preta, da ECA/USP, e Temas para Dança Brasileira, da Editora Sesc/SP, evidenciando a relevância da noção em questão, assim como a necessidade de sua problematização no campo da arte contemporânea brasileira. É nesse escopo que se pretende incluir o presente artigo, que visa a olhar de perto para a dramaturgia do coreógrafo brasileiro Borelli, com um recorte especifico em três de suas obras kafkianas: Metamorfose, Carta ao Pai e O processo.

\section{Metodologia}

O grande desafio desta pesquisa é definir uma abordagem metodológica para apreender os processos criativos da obra de Borelli, para, então, mapear a criação da dramaturgia na dança contemporânea. Assim como, a partir da noção de cartografia de Deleuze e Guatari², o tema da pesquisa aparece para o pesquisador com o próprio ato de pesquisar, foi ao acompanhar os ensaios da companhia em questão que o tema deste artigo foi se tornando mais claro e preciso ${ }^{3}$. Ao observar o processo de ensaio/direção da companhia de Borelli, o reconhecimento de dispositivos foi se definindo e um método de análise foi se delineando.

Se, para Deleuze, um dispositivo “(...) é um início de um novelo, um conjunto multilinear. Ele é composto de linhas de natureza diferentes", (DELEUZE; GUATARI, 1977, p. 30) o novelo, nesse caso, foi se desenrolando na prática cotidiana da observação dos ensaios, na repetição de diálogos, nas referências e nas imagens que emergem dessa escuta.

Portanto, compreender que o percurso é mutante e que o território dessa pesquisa é vivo e continuamente móvel é fundamental. Desse modo, procurar uma dramaturgia específica, a dramaturgia de Borelli, requer que o olhar esteja constantemente pronto para uma mudança de foco: precisa ser um olhar atento, mas que não pode estar preso. É preciso experimentar esse fazer, a fim de encontrar o objeto e reconhecê-lo em suas mais variadas formas. A leitura atenta dos livros de Kafka pos-
2.

"A Cartografia como método de pesquisaintervenção pressupõe uma orientação do trabalho do pesquisador que não se faz de modo prescritivo, por regras já prontas nem com objetivos previamente estabelecidos" (PASSOS, 2010, p. 17).

3.

Cabe destacar que este artigo faz parte da pesquisa de doutorado da autora, ainda em andamento. 
sibilita o surgimento de pistas que podem ajudar o desenvolvimento da pesquisa.

\section{Dramaturgia da Violência}

Deleuze e Guatari se perguntam: "como entrar na obra de Kafka?” (DELEUZE; GUATARI, 1977, p. 32). Para a dupla de filósofos franceses, essa obra trata de um rizoma, de uma toca. São diversas as entradas possíveis para a literatura kafkiana, e Borelli optou pelo corpo como meio de acesso a este conhecimento. Certamente, um coreógrafo que se propõe a dialogar com a obra densa e sinuosa do escritor tcheco precisa fazer esta leitura por meio da pesquisa do movimento, do próprio corpo, mas mesmo o corpo único do ser humano é rizomático, e tem também suas diversas tocas e possíveis acessos.

Em seu extenso diálogo com a obra de Kafka, Borelli levou para a cena seis obras inspiradas por textos originais. Aqui, como mencionado, faz-se um recorte na Trilogia Kafka, composta pelas coreografias inspiradas pelas obras já mencionadas. Essa escolha se justifica pelo fato de tais obras terem uma continuidade, o que, de certo modo, lhes confere uma dimensão única, podendo, até mesmo, ser entendidas como uma espécie de "tríptico coreográfico".

Passear entre as obras kafkianas de Borelli é transitar pelo subsolo da dança. Certamente Borelli faz jus ao rótulo de coreógrafo underground, mas não se trata aqui de sua fama de criador difícil e genioso. O subterrâneo está presente em suas escolhas dramatúrgicas, que funcionam como as tocas de Kafka. A luz é pouca, mas não escura. A movimentação é árida, mas não é pouca; o figurino é frio, mas sufoca. A atmosfera é densa, como em um anoitecer em pleno inverno tcheco.

Sandro Borelli resiste às tentações de concessão. Se Kafka não abre concessões, o coreógrafo também não as abrirá. Percebe-se, nessa trilogia, um condensado de forças, um discurso rouco, pessoas solitárias, silêncio. As narrativas animalistas de Kafka, sua literatura marginal e solitária propõem questões que deverão ser desenvolvidas no percurso dessa pesquisa. Assim, várias perguntas são suscitadas: de que forma tais características existem nos corpos que dançam na Companhia de Borelli? De que maneira Kafka está presente nessa dramaturgia de dança?

A dança, nesse tríptico, resiste em momentos nos quais os corpos são interditados. Tais corpos se tocam, muitas vezes, apenas pelo contato de suas roupas, que, por sua vez, trocam de corpos. O palco pode ter espelhos em mancebos - como em Carta ao Pai - bancos ou cadeiras, mas está vazio. Plenamente 
vazio. O desconforto da trilha sonora é provocado pela composição de ruídos e de sons estranhos, o tempo e o espaço dilatados dos movimentos insistem em uma linearidade monocórdica e os objetos de cena são elementos que, isoladamente, seriam inofensivos ou até inexpressivos, mas na construção coreográfica de Borelli - que insiste em pisotear, carregar e derrubar seus bailarinos - tornam-se brutais e violentos, assim como a vida que Kafka brilhantemente nos mostra em sua "Metamorfose".

Desse modo, a dramaturgia emerge violenta, não apenas como recurso espetacular, mas em função da contundência do que é construído em cena, a partir da parceria que é gerada entre o artista e o público - iniciado ou não na obra de Kafka - que, por sua vez, é estímulo, embora não pré-requisito, para a leitura desse texto cênico em particular.

\section{A Violência da Dramaturgia}

Escolher tratar especificamente da Trilogia Kafka, de Sandro Borelli, deve-se tanto às suas vicissitudes autorais quanto pela possibilidade de, ao tratar de um caso concreto, observar-se de que modo a dramaturgia na dança pode construir sentidos.

São diversas as faces da dramaturgia que podem ser apontadas como potenciais catalisadores para a construção de sentidos, o que leva a outro aspecto fundamental - que não será tratado nesse artigo, em função do limite do mesmo - que é o da própria noção de sentido. Por ora, sugere-se a conceituação de sentido como aquilo que transcende o significado, que está mais relacionado ao universo sensorial e perceptivo do que ao campo intelectual e racional. Como em Deleuze, para quem é possível apreender que "(...) o sentido não é nunca apenas um dos dois termos de uma dualidade que opõe as coisas e as proposições, os substantivos e os verbos, as designações e as expressões, já que é também fronteira, o corte ou a articulação entre os dois (...)" (Deleuze, 2007, p. 32).

A técnica dos bailarinos; o corpo - máquina que jamais é simplesmente técnica, mas que fala, também, por meio de suas atividades adjacentes, de suas pausas, de seus respiros e repousos -; a teatralidade, que pode ser compreendida a partir da definição de Pavis', somado aos materiais, que, como define Bonfitto, podem ser "(...) qualquer elemento que adquire uma função no processo de construção da identidade do próprio objeto" (BONFITTO, 2002, p. 17), todas essas faces ou, ainda, ferramentas da dramaturgia, estão a serviço (ou desserviço) do coreógrafo e dos bailarinos, para que se possa
4.

"Conceito formado provavelmente com base na mesma oposição que literatura/literalidade. A Teatralidade seria aquilo que, na representação ou no texto dramático, é especificamente teatral (ou cênico)..." (PAVIS, 2007, p. 372). 
construir um sentido, ou vários, a partir da construção e encenação do espetáculo.

Desse modo, a dramaturgia, em Borelli, acontece com toda a sua violência, pois é contundente, visceral. Ela cria um amálgama entre o texto de Kafka e a cena, sem recorrer a recursos literais de tradução; é representativa sem ser necessariamente figurativa.

Neste ponto, ao contrário de promover um impasse, ou de buscar respostas afirmativas que definam um modelo de dramaturgia em dança, na dança ou para a dança, o que se pretende é alimentar sua reflexão e traçar um diálogo fecundo com artistas e pesquisadores que comungam um interesse por essa instigante e ampla noção. 


\section{REFERÊNCIAS}

BARBA, Eugenio. Queimar a Casa. Origens de um Diretor. Sāo Paulo: Perspectiva, 2010.

BONFITTO, Matteo. O Ator Compositor. São Paulo: Perspectiva, 2002.

DELEUZE, Gilles; GUATARI, Felix. Kafka, Por uma Literatura Pobre. Rio de Janeiro: Imago, 1977.

KAFKA, Franz. O processo. São Paulo: Companhia das Letras: 1997.

PASSOS, Eduardo e KASTRUP, Virginia. Pistas para o Método Cartográfico. Porto Alegre: Editora Sulina, 2010.

SADDI, Fatima. Título do capítulo. In: NORA, sigrid (Org). Temas para Dança Brasileira. São Paulo: Edições SESC SP, 2010. (AUTOR, POR GENTILEZA, COMPLETAR A REFERÊNCIA). 